\title{
ANTERIOR IMPINGEMENT OF THE ANKLE TREATED BY ARTHROSCOPIC REMOVAL OF BONY SPURS
}

\author{
D. J. OGILVIE-HARRIS, N. MAHOMED, A. DEMAZIÈRE
}

From the University of Toronto and the Toronto Hospital, Canada

We reviewed 17 patients after arthroscopic resection for anterior impingement in the ankle. All had had painful limitation of dorsiflexion which had failed to respond to conservative treatment.

Review at an average of 39 months showed very significant improvements in levels of pain, swelling, stiffness, limping and activity. There was a significant improvement in the range of dorsiflexion but not of plantar flexion. One poor result was due to a superficial infection, and two other patients had residual numbness of the foot which persisted for several months.

J Bone Joint Surg [Br] 1993; 75-B :437-40.

Received 17 June 1992; Accepted 3 September 1992

One of the causes of anterior ankle pain is abnormal bony spurring which projects into the tibiotalar joint from the tibia and often from the talus. Dorsiflexion of the ankle causes impingement, limits movement, and produces pain.

The cause is not clear but it is commonly seen in athletes and dancers, and is probably due to repetitive

Table I. Scoring system used to assess results in five categories (see Table II)

\begin{tabular}{lllll}
\hline & $\begin{array}{l}\mathbf{1} \\
\text { Poor }\end{array}$ & $\begin{array}{l}\mathbf{2} \\
\text { Fair }\end{array}$ & $\begin{array}{l}\mathbf{3} \\
\text { Good }\end{array}$ & $\begin{array}{l}\mathbf{4} \\
\text { Excellent }\end{array}$ \\
\hline Pain & Severe & Moderate & Mild & None \\
Swelling & $\begin{array}{l}\text { Moderate/ } \\
\text { severe }\end{array}$ & $\begin{array}{l}\text { Mild with } \\
\text { ADL }^{*}\end{array}$ & $\begin{array}{l}\text { With } \\
\text { exercise }\end{array}$ & $\begin{array}{l}\text { None/ } \\
\text { minimal }\end{array}$ \\
Stiffness & $\begin{array}{l}\text { Minimal } \\
\text { motion }\end{array}$ & $\begin{array}{l}\text { Painful } \\
\text { deficit }\end{array}$ & $\begin{array}{l}\text { Mild } \\
\text { deficit }\end{array}$ & $\begin{array}{l}\text { None/ } \\
\text { minimal }\end{array}$ \\
Activity & $\begin{array}{l}\text { Severe } \\
\text { (cane/crutch) }\end{array}$ & Moderate & Slight & None \\
\hline
\end{tabular}

* activities of daily living

D. J. Ogilvie-Harris, FRCS C, Chief of Orthopaedics and Smith \& Nephew Richards Professor

N. Mahomed, MD, Resident, Orthopaedic Residency Program A. Demazière, MD, Research Fellow

Room 1-032, Edith Cavell Wing, Toronto Western Hospital, 399

Bathurst Street, Toronto, Ontario, Canada M5T 2S8.

Correspondence should be sent to Professor D. J. Ogilvie-Harris.

(C)1993 British Editorial Society of Bone and Joint Surgery $0301-620 \mathrm{X} / 93 / 3546 \$ 2.00$ minor trauma. The condition was first described by Morris (1943) who called it athlete's ankle; McMurray (1950) reported good results from excision of the spurs, naming it footballer's ankle. Since then it has been reported in many athletes who use repetitive and forceful dorsiflexion movements of the ankle and is usually termed anterior impingement syndrome (O’Donoghue 1957; Brodelius 1960; Parkes et al 1980; Hardaker, Margello and Goldner 1985; Martin et al 1989; Parisien 1991).

We report the results of arthroscopic resection of the bony spurs in 17 patients.

\section{PATIENTS AND METHODS}

Arthroscopic debridement was performed on 17 consecutive patients with persistent anterior ankle pain and restricted dorsiflexion. Their ages ranged from 19 to 51 years (mean 31). Most had had at least six months' conservative treatment, by active and passive stretching and by strengthening exercises, with short courses of anti-inflammatory drugs. In all patients, preoperative lateral radiographs clearly showed a bony spur or osteophyte on the tibia, with a corresponding spur on the talus in all but one. Thirteen showed mild narrowing of the radiological joint space anteriorly.

We rated symptoms on a four-point scale both before and after operation, recording pain, swelling, stiffness, limping and activity (Table I). The ranges of dorsiflexion and plantar flexion were measured to the nearest $5^{\circ}$ by an active assisted technique (Bohannon, Tiberio and Zito 1989). Subjective assessments were made of ability to return to preoperative sporting activities, degree of improvement, justification of the operation and repeat of the operation if this became necessary.

Preoperative assessments were all performed by the operating surgeon (DO-H), but the postoperative assessments were by the other authors. They examined patients who had had arthroscopy for either bony spurs or other non-related conditions such as osteochondritis dissecans. The assessors were not aware of the diagnosis. In this way an attempt was made to achieve an objective judgement. All patients had standard anteroposterior, lateral and mortice radiographs of the ankle at review.

Results were analysed using the Wilcoxon rank-sum method, and changes in dorsiflexion and plantar flexion were studied by analysis of variance (ANOVA). Statist- 
Table II. Grading of five parameters in 17 patients before (pre) and after (post) arthroscopic treatment, with $p$ value of difference (Wilcoxon rank-sum test)

\begin{tabular}{lrrrrr}
\hline & Grade & & & \\
\cline { 2 - 6 } & 1 & 2 & 3 & 4 & $\begin{array}{r}\text { P value of } \\
\text { difference }\end{array}$ \\
\hline $\begin{array}{c}\text { Pain } \\
\text { Pre }\end{array}$ & 2 & 10 & 5 & & \\
Post & & 1 & 2 & 14 & 0.0004 \\
$\begin{array}{c}\text { Swelling } \\
\text { Pre }\end{array}$ & & & & & \\
Post & & & 1 & 16 & 0.027 \\
$\begin{array}{c}\text { Stiffness } \\
\text { Pre }\end{array}$ & & & 6 & 11 & \\
Post & & & 1 & 16 & 0.043 \\
Limping & & & & & \\
$\begin{array}{l}\text { Pre } \\
\text { Post }\end{array}$ & 4 & 8 & 5 & \\
$\begin{array}{c}\text { Activity } \\
\text { Pre }\end{array}$ & 1 & 2 & 14 & 0.002 \\
Post & 10 & 7 & & \\
\hline
\end{tabular}

Table III. Pre- and postoperative ranges of dorsiflexion and plantar flexion, with $p$ value of difference by analysis of variance (ANOVA)

\begin{tabular}{lrrrr}
\hline & Mean & Range & SD & $\begin{array}{r}\text { p value of } \\
\text { difference }\end{array}$ \\
\hline $\begin{array}{l}\text { Dorsiflexion } \\
\text { Pre }\end{array}$ & 3 & -5 to 10 & 4.4 & \\
$\quad$ Post & 12 & 5 to 20 & 4.7 & $<0.0001$ \\
& & & & \\
$\begin{array}{l}\text { Plantar flexion } \\
\text { Pre }\end{array}$ & 50 & 40 to 60 & 5.4 & \\
Post & 52 & 45 to 65 & 5.6 & 0.096 \\
\hline
\end{tabular}

ical significance was assumed for $p$ values of less than 0.05 .

Arthroscopic procedure. Ankle arthroscopy was performed as day-surgery, under general anaesthesia and with a tourniquet at thigh level. A needle was inserted just lateral to the tendon of peroneus tertius and the ankle was inflated with 15 to $20 \mathrm{ml}$ of saline. A small longitudinal skin incision allowed a $4.5 \mathrm{~mm} 30^{\circ}$ angled arthroscope to be inserted through an anterolateral portal.

Care was taken to pass the arthroscope across the anterior aspect of the joint and not across the dome of the talus and a separate anteromedial portal was made just medial to the tibialis anterior tendon to allow inflow and outflow of saline. Instruments were inserted through the anteromedial portal.

A gas-driven pressure irrigation system was used with a $3.5 \mathrm{~mm}$ full-radius resector to clear the anterior synovium and to define the anterior tibial and superior talar bony spurs. A $4 \mathrm{~mm}$ burr was then used to remove the spurs, resecting back until the normal cortical bone of the anterior tibia could be seen. This could be easily distinguished from the soft cancellous bone of the spur, and the tibial surface was smoothed off using the $3.5 \mathrm{~mm}$ full radius resector. A similar procedure was carried out on the superior neck of the talus.
The whole ankle was examined by passing the arthroscope gently over the dome of the talus. This was made possible by opening the ankle laterally by manual distraction in mid-plantar flexion. No distraction device was used.

After operation and a thorough wash-out, $20 \mathrm{ml}$ of $0.25 \%$ buvipicaine were instilled into the joint and the incision was sutured. Patients were allowed to take full weight, according to comfort, with a firm bandage around the ankle. A rigorous rehabilitation programme was started after one week, which included ice packs and active and passive range-of-movement exercises. A tilt board was used for proprioceptive training, and the anterior and posterior muscles of the calf and foot were strengthened. Sport was resumed after six weeks in a graduated protected fashion, with special care to make sure that footwear was adequate for its purpose, such as properly fitting running shoes.

\section{RESULTS}

All 17 patients were reviewed at 24 months to 68 months after operation (mean 39 months). They showed a significant improvement in all five criteria (Table II).

Before operation, ankle dorsiflexion ranged from $-5^{\circ}$ to $10^{\circ}$ (mean $3^{\circ}$; Table III); postoperatively, this became $5^{\circ}$ to $20^{\circ}$ (mean $12^{\circ}$ ), a highly significant change $(p=0.0001)$. Plantar flexion, however, showed no significant change $(p=0.096)$. Only one patient failed to return to his sporting activities; this patient felt that there had been no improvement and one other thought that there had been only slight improvement. The other 15 reported substantial improvement.

Complications. The patient who had no improvement and considered that the procedure was not worthwhile had suffered a superficial infection of the anteromedial arthroscopy portal five days postoperatively. Suture removal and antibiotics produced resolution but the patient had a poor result, with no change from preoperative status. Two other patients had mild anterior numbness after the anterior instrumentation probably due to pressure on superficial nerves. The numbness resolved completely over a period of months in both cases.

Radiography. Follow-up radiographs showed no residual spurs in 15 of the 17 patients (Figs 1 to 3), but in one a spur had partially recurred at five years and in another there appeared to have been incomplete spur removal. Eight patients showed evidence of mild degenerative joint disease of the mid-tarsal joint (Fig. 2).

\section{DISCUSSION}

The cause of anterior spurring is unknown, but it appears to be due to repetitive minor trauma rather than any one episode of injury. It is seen in runners and dancers and in athletes who forcibly dorsiflex their ankles. The associa- 


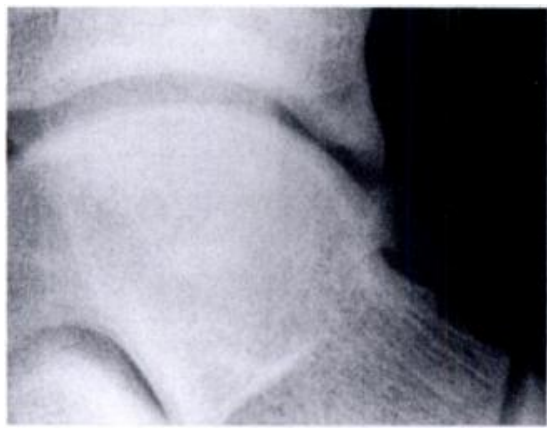

Fig. Ia

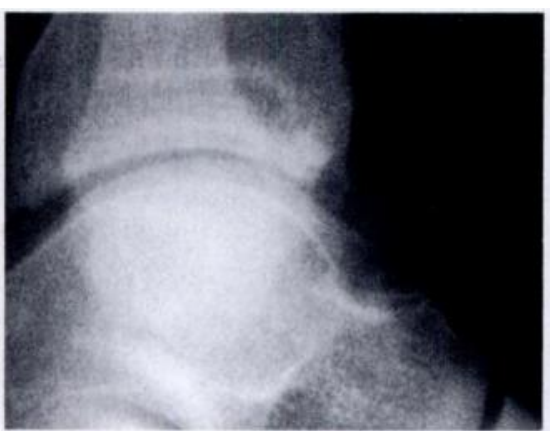

Fig. 1b

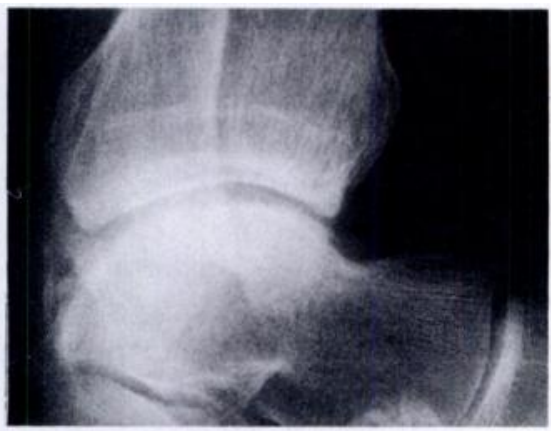

Fig. 1c

Figure $1 \mathrm{a}$ - Anterior bony spurs on the tibia and the neck of the talus. Figure $1 \mathrm{~b}$ - One week after arthroscopic removal there is some residual haziness but both spurs have been resected. Figure lc - Four years later there is remodelling of the anterior tibia and superior talar neck, and the mild anterior joint-space narrowing has not progressed.

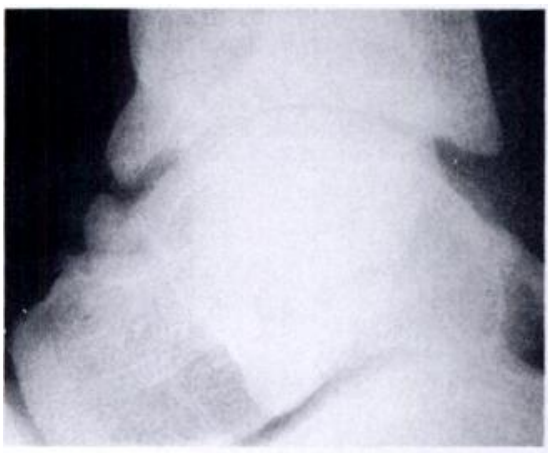

Fig. 2a

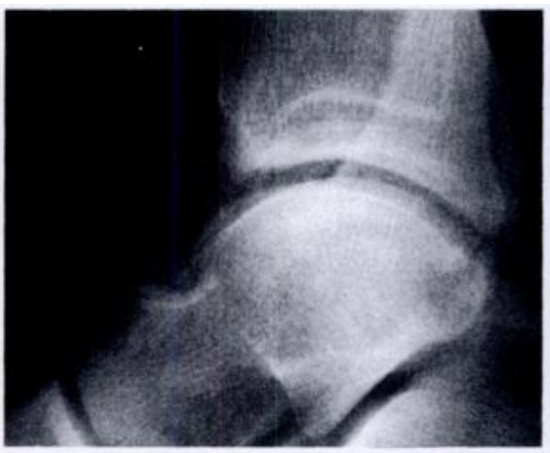

Fig. 2b

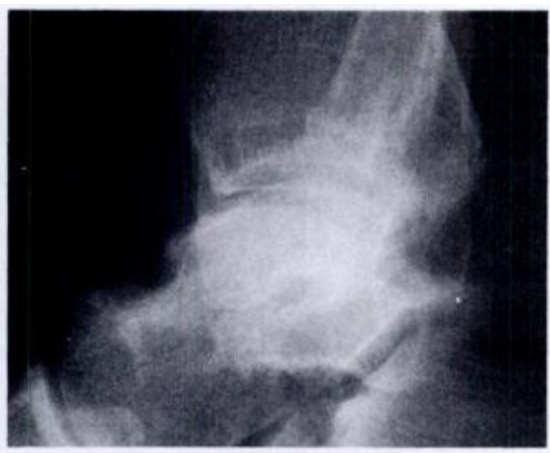

Fig. 2c

Figure 2a - Large anterior bony spurs on tibia and talus with slight joint-space narrowing. Figure $2 b-T w o$ weeks after resection the anterior tibia and the talar neck are recontoured. Figure $2 c$ - After 47 months there is further remodelling, but some evidence of degenerative change in the mid-foot.

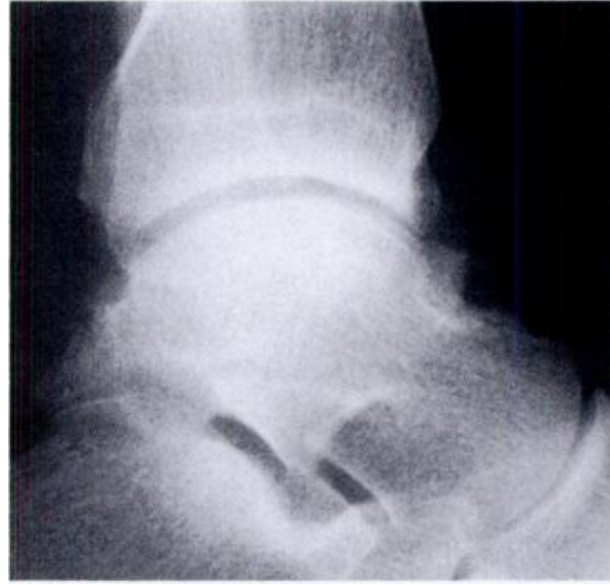

Fig. 3a

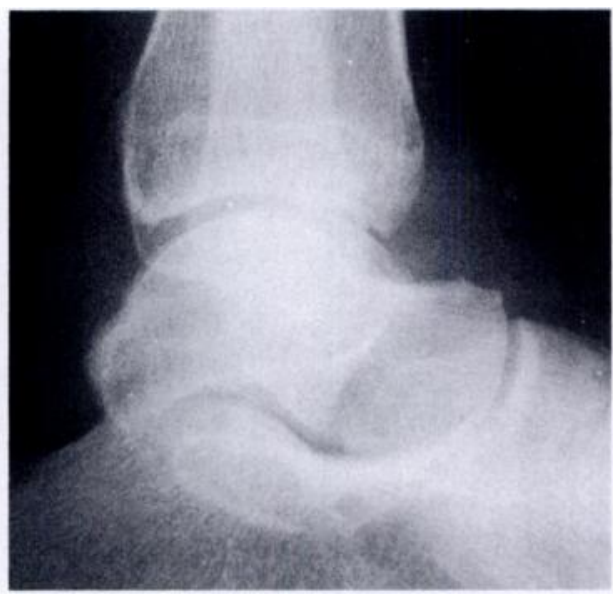

Fig. 3b

Figure 3a - Preoperative anterior tibial and superior talar bony spurs. Figure $3 \mathrm{~b}$ - No recurrence of the spurs after five years.

tion with minor narrowing of the anterior joint space and mid-tarsal changes suggests that anterior spurs may be part of an early degenerative process (McDougall 1955; O’Donoghue 1957; Brodelius 1960).

Operative arthroscopy for osteoarthritis of the ankle has not been successful (Hardaker et al 1985; Biedert 1991; Demazière and Ogilvie-Harris 1991), and we excluded patients with obvious osteoarthritis. Anterior impingement needs to be distinguished from anterolateral impingement (Ferkel et al 1991), in which pain is localised to the anterolateral corner of the ankle, radiographs are negative, and MRI usually shows chronic anterolateral synovitis with chondromalacia of the talus.

Conservative treatment for anterior impingement of the ankle often fails, and arthroscopic removal of the spurs carries a relatively low risk, although the risk of 
infection around the portals seems to be higher than in the knee (D'Angelo and Ogilvie-Harris 1988; Ferkel and Fischer 1989; Barber, Click and Britt 1990; Demazière and Ogilvie-Harris 1991). We now use prophylactic antibiotics for the procedure (D'Angelo and OgilvieHarris 1988).

We employed standard anteromedial and anterolateral portals (Gollehon and Drez 1983; Voto et al 1989). In view of the incidence of anterior numbness due to the proximity of the superficial sensory nerves (Voto et al 1989; Barber et al 1990; Demazière and Ogilvie-Harris 1991) we consider it worthwhile to warn the patient preoperatively of this.

Open removal of the anterior tibial and talar bony spurs was first described by McMurray (1950), reporting six patients all of whom returned to sport. McDougall (1955) also had success in 11 of 12 patients after operative treatment, but pointed out that conservative treatment had produced reasonable results in 14 of 17 patients. Other surgeons have also reported good results from open

\section{REFERENCES}

Barber FA, Click J, Britt BT. Complications of ankle arthroscopy. Foot Ankle 1990; 10:263-6.

Biedert R. Anterior ankle pain in sports medicine: etiology and indications for arthroscopy. Arch Orthop Trauma Surg 1991; 110:293-7.

Bohannon RW, Tiberio D, Zito M. Selected measures of ankle dorsiflexion range of motion. Foot Ankle 1989; 10:99-103.

Brodelius A. Osteoarthritis of the talar joints in footballers and ballet dancers. Acta Orthop Scand 1960; 30:309-14.

D'Angelo GL, Ogilvie-Harris DJ. Septic arthritis following arthroscopy, with cost/benefit analysis of antibiotic prophylaxis. Arthroscopy $1988 ; 4: 10-4$

Demazière A, Ogilvie-Harris DJ. Operative arthroscopy of the ankle: 107 cases. Rev Rhum 1991 ; 58:93-7.

Ferkel RD, Fischer SP. Progress in ankle arthroscopy. Clin Orthop $1989 ; 240: 210-20$.

Ferkel RD, Karzel RP, Del Pizzo W, et al. Arthroscopic treatment of anterolateral impingement of the ankle. Am J Sports Med 1991; 19:440-6.

Gollehon DL, Drez D. Ankle arthroscopy: approaches and technique. Orthopedics 1983; 6:1150-2. excision (O’Donoghue 1957; Brodelius 1960; Parkes et al 1980; Hawkins 1988).

Removal of an anterior tibial bony spur has been described in other arthroscopic series (Parisien 1991). Ferkel and Fischer (1989) reported excision of osteophytes in 12 patients, and had similar complications to us including anterior numbness. Biedert (1991) operated on 21 patients with a mixture of pathologies causing anterior ankle pain: two-thirds did well, but degenerative changes predisposed to a poor result.

Conclusions. Arthroscopic resection of the anterior tibial and superior talar bony spurs is an effective treatment for anterior impingement in the ankle. The procedure is recommended for patients with persistent anterior ankle pain and loss of dorsiflexion after conservative management has failed.

No benefits in any form have been received or will be received from a commercial party related directly or indirectly to the subject of this article.

Hardaker WT Jr, Margello S, Goldner JL. Foot and ankle injuries in theatrical dancers. Foot Ankle 1985; 6:59-69.

Hawkins RB. Arthroscopic treatment of sports-related anterior osteophytes in the ankle. Foot Ankle 1988; 9:87-90.

Martin DF, Baker CL, Curl WW, et al. Operative ankle arthroscopy: long-term follow-up. Am J Sports Med 1989; 17:16-23.

McDougall A. Footballer's ankle. Lancet 1955; 2:1219-20.

McMurray TP. Footballers ankle. J Bone Joint Surg [Br] 1950; 32 B:68-9.

Morris LH. Athletes ankle. J Bone Joint Surg 1943; $25: 220$.

O'Donoghue DH. Impingement exostoses of the talus and tibia. $J$ Bone Joint Surg [Am] 1957; 39-A :835.

Parisien JS. Arthroscopic surgery in osteocartilaginous lesions of the ankle. In: McGinty JB, ed. Operative arthroscopy. New York, etc Raven Press, 1991; 739-41.

Parkes JC, Hamilton WG, Patterson AH, Rawles JG. The anterior impingement syndrome of the ankle. J Trauma $1980 ; 20: 895-8$.

Voto SJ, Ewing JW, Fleissener PR, et al. Ankle arthroscopy: neurovascular and arthroscopic anatomy of standard and trans-achilles tendon portal placement. Arthroscopy 1989:5:41-6. 